\title{
Supporting the Initial Work of Evidence-Based Improvement Cycles Through a Data-Intensive Partnership 1,2,3
}

\author{
Alex J. Bowers \\ Teachers College, Columbia University \\ Bowers@tc.edu
}

\author{
Andrew E. Krumm \\ University of Michigan \\ aekrumm@med.umich.edu
}

\begin{abstract}
:
Purpose: Currently in the education data use literature there is a lack of research and examples that consider the early steps of filtering, organizing, and visualizing data to inform decision making. The purpose of this study is to describe how school leaders and researchers visualized and jointly made sense of data from a common learning management system (LMS) used by students across multiple schools and grades in a charter management organization operating in the United States. To make sense of LMS data, researchers and practitioners formed a partnership to organize complex data sets, create data visualizations, and engage in joint sensemaking around data visualizations to begin to launch continuous improvement cycles.

Design: We analyzed LMS data for $n=476$ students in Algebra I using hierarchical cluster analysis heatmaps. We also engaged in a qualitative case study that examined the ways in which school leaders made sense of the data visualization to inform improvement efforts.

Findings: The outcome of this study is a framework for informing evidence-based improvement cycles using large, complex datasets. Central to moving through the various steps in the proposed framework are collaborations between researchers and practitioners who each bring expertise that is necessary for organizing, filtering, and visualizing data from digital learning environments and administrative data systems.

Originality: We propose an integrated cycle of data use in schools that builds on collaborations between researchers and school leaders to inform evidence-based improvement cycles.
\end{abstract}

\footnotetext{
${ }^{1}$ This document is a preprint of this manuscript published in the journal Information and Learning Sciences. Citation:

Bowers, A.J., Krumm, A.E. (2021) Supporting Evidence-Based Improvement Cycles Through a Data-Intensive Partnership. Information and Learning Sciences, 122(9/10) 629-650. https://doi.org/10.1108/ILS09-2020-0212

$\frac{1}{2}$ This material is based upon work supported by the National Science Foundation under Grant No. DRL-1444621; SMA-1338487. Any opinions, findings, and conclusions or recommendations expressed in this material are those of the authors and do not necessarily reflect the views of the National Science Foundation.

${ }^{3}$ Acknowledgements: We thank Mingyu Feng and Timothy Podkul for their discussions of the early stages of this study, and their work with the schools and leadership throughout the partnership detailed in the study.
}

Bowers \& Krumm (2021)

\section{Keywords:}

Data Analysis, Data Interpretation, Data Use, Data Driven Decision Making, Evidence Based Improvement Cycles, Researcher Practitioner Partnerships, Data Science, School Leadership, Algebra I, Cluster Analysis, Case Study, Visual Data Analytics, Heatmaps

\section{INTRODUCTION:}

\begin{abstract}
It was a totally different way of visualizing data that I think we haven't seen before... It was just a really, really interesting way to think about data. Because we think about it in simpler terms here and so it's nice to see the larger possibilities with what we can do with the data that we have. -Participant CMO education leader
\end{abstract}

Strategies for turning newly expanding volumes of data into a resource for school and instructional improvement is an important area of research and practice (Agasisti \& Bowers, 2017; Bowers, Bang, Pan, \& Graves, 2019; Farley-Ripple, Jennings, \& Jennings, 2021; Krumm, Means, \& Bienkowski, 2018; Mandinach, Friedman, \& Gummer, 2015; Schildkamp, Poortman, Luyten, \& Ebbeler, 2017). This broad topic spans multiple areas of education research including data-driven decision making, education policy studies, and educational data science. Educational data science is an emerging term that encompasses the fields of learning analytics, educational data mining, artificial intelligence in education, and education leadership data analytics (Agasisti \& Bowers, 2017; Bowers et al., 2019; Piety, 2019; Piety, Hickey, \& Bishop, 2014). Using data for school and instructional improvement is a complex process that has been studied and intervened on in a variety of ways with varying degrees of success (Coburn \& Turner, 2011; Halverson, 2010; Harris Little, Cohen-Vogel, Sadler, \& Merrill, 2019; Mandinach \& Schildkamp, 2021). In this paper, we report on a case study of the first steps of a partnership-based approach that sought to put educational data scientists closer to the work of practitioners and practitioners closer to the work of data scientists (Penuel \& Gallagher, 2017), with a particular focus on the first two steps of the work of data use in schools of organizing, filtering, analyzing, and visualizing. 
Both federal and state policies have motivated teachers and administrators to engage in data-driven improvement cycles (Cho \& Wayman, 2015; Farley-Ripple et al., 2021; Mandinach \& Schildkamp, 2021; Schildkamp, 2019; Wachen, Harrison, \& Cohen-Vogel, 2018). To date, important parts of this literature have been practitioner-focused (Bowers, 2017; Coburn \& Turner, 2012), addressing issues like using student-level data as a context to build trusting and collaborative relationships between teachers in schools as they develop capacity for continuous improvement (Bambrick-Santoyo, 2010; Boudett, City, \& Murnane, 2013; Bryk, Gomez, \& Grunow, 2010; Cosner, 2014; Datnow, Choi, Park, \& St. John, 2018; FarleyRipple \& Buttram, 2015; Lasater, Albiladi, Davis, \& Bengtson, 2020; Riehl, Earle, Nagarajan, Schwitzman, \& Vernikoff, 2018; Supovitz \& Morrison, 2015; Wayman \& Stringfield, 2006).

As new types of data have become available and accessible, there is an open question as to whether traditional data analysis tools and workflows are up to the challenge of making sense of, for example, students' activity within multiple digital learning environments (Agasisti \& Bowers, 2017; Bowers, 2021; FarleyRipple et al., 2021; Krumm et al., 2018; Piety, 2019). Building on the growing scholarship around research-practice partnerships in schools (Penuel et al., 2020), the partnership described in this paper between researchers and a charter management organization (CMO) operating in the Western United States set out to wrangle, explore, and model thousands of observations across hundreds of students to answer teachers' and leaders' questions related to students' use of a common learning management system (LMS). Through intentional cycles of design and reflection, the partnership also sought to understand the ways in which researchers and practitioners can collaborate around gathering, analyzing, and interpreting data from multiple digital learning environments and administrative data systems.

This paper is organized as follows. First, we present a theory of action that the partnership developed and used to organize partnership activities as well as to identify potential contributions to research on data driven decision making, educational data science, and data use practices. Thus, this theory of action represents an analysis of data use research that helped in crafting design conjectures used to orient the partnership's work (e.g.,) (Cobb \& Jackson, 2012). As one study from the larger partnership, this paper describes the initial improvement cycle undertaken around data that captured students' assessment taking behaviors that were collected by the CMO's LMS. While the overall project was organized as a design research effort that included iterative, theory-driven cycles, this paper is structured as a case study of two early partnership meetings that were organized around a handful of data visualizations. After presenting the partnership's theory of action, we describe the data visualization that anchored the meetings around which researchers and practitioners engaged in joint sensemaking. Based on the dynamics of these meetings and the roles of the data product and researchers, we reflect on the potential for more partnership-based data-intensive projects to help school leaders overcome the challenges of working with new and novel data sources.

\section{A THEORY OF ACTION FOR DATA USE IN SCHOOLS}

To develop the partnership's "data use theory of action," we built on existing research (Coburn \& Turner, 2012; Ikemoto \& Marsh, 2007; Lai \& Schildkamp, 2013; Mandinach, Honey, \& Light, 2006; Mandinach, Honey, Light, \& Brunner, 2008; Marsh, 2012; Schildkamp \& Kuiper, 2010; Schildkamp \& Poortman, 2015; Schildkamp, Poortman, \& Handelzalts, 2016; Tichnor-Wagner, Wachen, Cannata, \& Cohen-Vogel, 2017) and adapted a figure from Marsh (2012, p.4). In Figure 1, the continuous improvement process starts with 1) data access and collection, then proceeds through 2) organization, filtering and analysis moving then to 3 ) knowledge generation through the work of teachers and administrators coming together around the evidence in which that knowledge is then 4) applied through action informed by the data with a subsequent impact on outcomes. The cycle then completes as 5) outcomes are assessed for effectiveness and then feed back into the data. At each stage in the process, information flows through feedback loops to inform decisions, creating a continuous cycle.

Important aspects of the research in the data use literature have focused on building trusting evidence-based environments (Cosner, 2014; Huguet, Marsh, \& Farrell, 2014; Marsh, Bertrand, \& Huguet, 2015; Riehl et al., 2018; Schildkamp \& Poortman, 2015; Schildkamp et al., 2016). The vast majority of this literature is focused on cultivating teachers' and administrators' ability to have high evidence, low inference conversations (Bowers, Shoho, \& Barnett, 2014; Schildkamp \& Poortman, 2015). This research focuses specifically on steps 3,4 and 5 in the theory of action (see Figure 1) (Datnow et al., 2018; Jimerson, Garry, Poortman, \& Schildkamp, in press; Supovitz \& Morrison, 2015) and is consonant with much of the current normative practitioner training literature around data use, such as Harvard University's DataWise (Boudett et al., 2013) and Bambrick-Santoyo's Driven by Data (Bambrick-Santoyo, 2010). To a lesser extent, some of the practitioner training literature has also focused on what data to examine (Bowers, 2009, 2017; Bowers et al., 2019), i.e., step 1 in the data use theory of action. For example, this training literature includes Popham's focus on the essentials of assessment for leading evidence-based practice in schools (Popham, 2010) and Bernhardt's strategies for working with data beyond test scores (Bernhardt, 2013). Indeed, recent research has shown that teachers more often focus on formative assessments as opposed to standardized test scores (Wilkerson, Klute, Peery, \& Liu, 2021). Across these examples of building trust, supporting low inference/high evidence collaborative conversations, and selecting data, the work of organizing, filtering, and analyzing data, i.e., step 2 , is only recently starting to gain attention. 


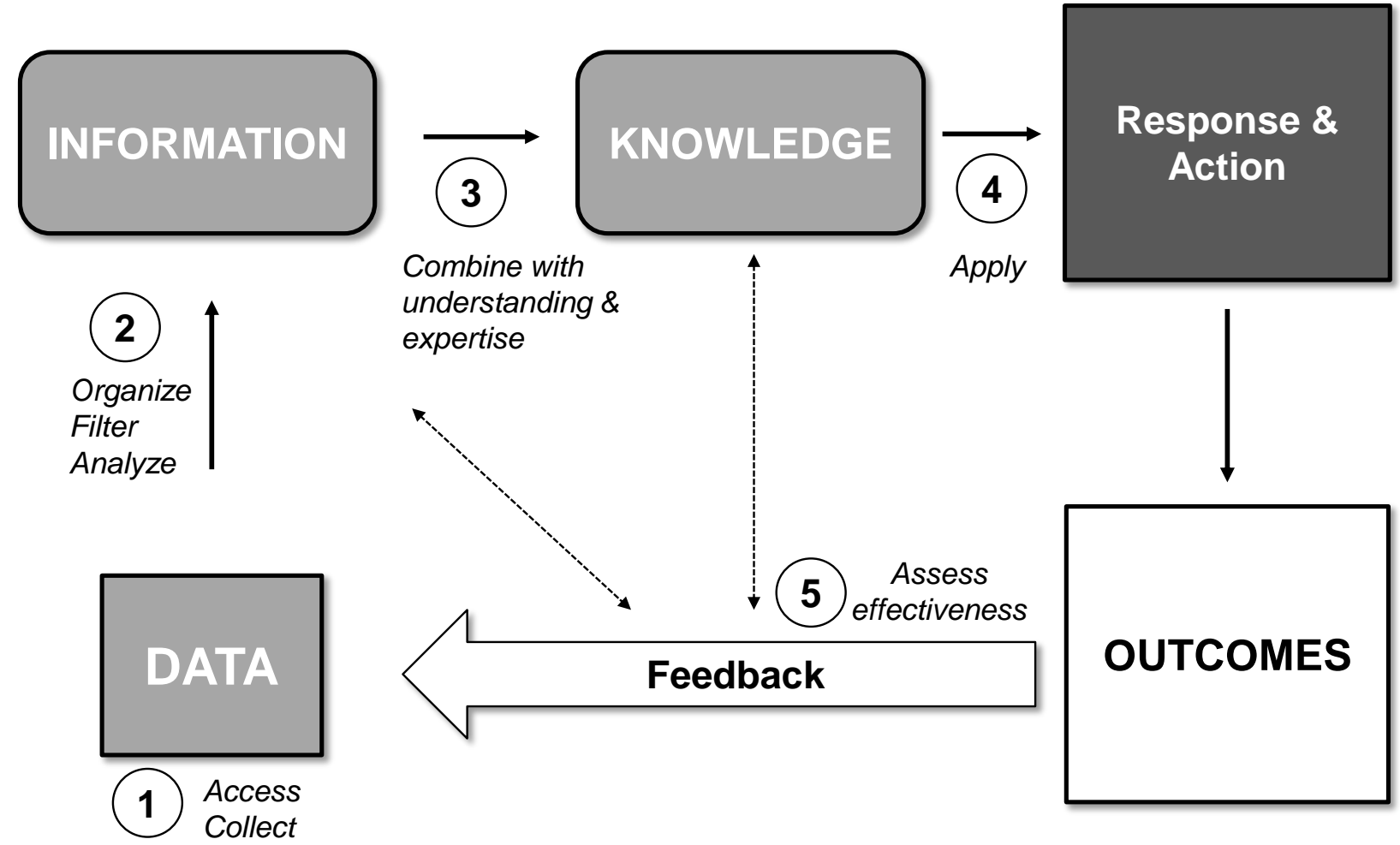

Figure 1: Data use theory of action for teachers, students, school administrators and central office staff adapted from: Coburn \& Turner (2012); Ikemoto \& Marsh (2007); Lai \& Schildkamp (2013); Mandinach, Honey, \& Light (2006); Mandinach, Honey, Light, \& Brunner (2008); Marsh (2012); Schildkamp \& Kuiper (2010); Schildkamp \& Poortman (2015); Schildkamp, Poortman, \& Handelzalts (2016).

\section{A Focus on Step Two of the Data Use Theory of Action}

While some attention has been paid to organizing, filtering, and analyzing traditional student assessment data in the recent literature (Agasisti \& Bowers, 2017; Farley-Ripple et al., 2021), evidence suggests that schools do not have adequate capability to locate, combine, and analyze data from digital learning environments and learning management systems (LMS) (Clow, 2014; Hao, Smith, Mislevy, von Davier, \& Bauer, 2016). The often messy work of bringing together multiple datasets as well as aligning student and teacher identifiers across longitudinal data files - known in the data science and data warehouse fields as Extract, Transform, Load (ETL) (Mukherjee \& Kar, 2017; Vassiliadis, 2009) - is being addressed by a growing number of researchers under the banner of learning analytics and educational data mining (i.e., data-intensive research). Researchers in these fields, for example, focus on developing data workflows and data pipelines that combine, analyze, and translate analyses into data products like predictive models and dashboards (Agasisti \& Bowers, 2017; Bienkowski, Feng, \& Means, 2012; Bowers, 2021; Fischer et al., 2020; Ifenthaler, 2021; Koedinger, D'Mello, McLaughlin, Pardos, \& Rosé, 2015; Krumm et al., 2018).
It is reasonable to question, however, whether or not data from digital learning environments can be valuable to practitioners outside of the dashboards and visualizations provided by the environments themselves (DiCerbo \& Kobrin, 2016; FarleyRipple et al., 2021). Researchers and technology developers have demonstrated the potential value of these data through products like early warning systems for course success and high school dropout prevention (Bowers, 2021; Ifenthaler, 2021). Using these data, researchers have also demonstrated how to effectively operationalize learning behaviors and strategies as well as how to intervene on them in order to improve downstream learning outcomes (R. S. J. d. Baker et al., 2006; Walonoski \& Heffernan, 2006). Furthermore, the idea of unobtrusive measurement and assessment has opened up the possibility of monitoring and supporting learners around behaviors like wheel spinning (Beck \& Gong, 2013), productive persistence (Krumm et al., 2016), perseverance (DiCerbo, 2014), gaming the system (R. S. Baker, Corbett, Koedinger, \& Wagner, 2004), and help seeking (Aleven, Roll, McLaren, \& Koedinger, 2016). While many of these behaviors are possible to identify in the data, they require interested potential users and the data to support educators' decision making. 
In contrast to this generally positive stance of the learning analytics literature, the evidence from recent data use practices research is less positive. Recent examples include low engagement by educators in popular data systems such as NWEA MAP (Farley-Ripple et al., 2021), few if any significant relationships between teacher instructional clicks in a data dashboard and student outcomes in a large US school district (Wayman, Shaw, \& Cho, 2017), and a tendency to reify problematic inferences about student knowledge and learning when observing teacher data team meetings to discuss individual student assessment answer data (Garner, Thorne, \& Horn, 2017). An issue rarely noted throughout the literature on school data use was recently highlighted by Selwyn et al. (in press) in that more often than not "data analytics" takes the form of having the "data person" in the school work in spreadsheets to create "simple frequency counts, colour-coding and modest crosstabulations" (p.13). Moreover, technological tools that were intended to support more inspired data analyses were, according to Selwyn and colleagues:

...largely inadequate and unhelpful forms of digital technology that were failing to 'support' the generation and use of data within the school... One key point was the limited capacity of schools' data systems to collate, store and share data with staff... Above all, was an overriding sense that people working within these schools (in contrast to any imagined possibilities) retained relatively limited ambitions for their actual use of data... Tellingly, any broader insights from these analyses were yet to translate into follow-up action within the school (p.14) (Selwyn, Pangrazio, \& Cumbo, 2021)

These authors conclude in this study that the advocacy for data use in schools "...needs to be set against the observation that schools do not appear to be particularly motivated to respond to (or even look for) novel insights and unexpected patterns and correlations in their data. In short, school data is not a place for surprises, counterintuition and 'outside-the-box' thinking”' (p.15) (Selwyn et al., 2021). Thus, for these reasons, in the present study we focus exclusively on the second step of the data use cycle of organize, filter and analyze (Figure 1), as an underresearched area in which we aim to describe the case of bringing together the domains of data visualization and education data science in application to a data use cycle to potentially cultivate school capacity to identify novel insights, unexpected patterns, and correlations in the data that can create surprise, and new ways for educators to see their own data from their school to make decisions.

While multiple researchers have helped to inform the process of implementing evidence-based improvement cycles in schools (Mandinach et al., 2006; Marsh, 2012; Schildkamp \& Ehren, 2013; Schildkamp et al., 2016; Tichnor-Wagner et al., 2017), the difficult work of turning data into actionable information is thus underdeveloped around data stemming from digital learning environments and large scale administrative data systems. This underdeveloped line of inquiry throws into relief the multiple capabilities needed to accomplish the goal of school and system improvement - from accessing and joining data to visualizing and interpreting data products (Bowers et al., 2019). The importance of finding ways to work with and learn from data stemming from digital platforms is only increasing due to the expanded use of digital technologies in classrooms and central offices (Bowers, 2021; Graves \& Bowers, 2018; Krumm \& Bowers, in press; Piety, 2019).

\section{Engaging in a Research-Practice Partnership for Data Use}

The current capability gaps that can exist around working with data from digital technologies can be addressed in multiple ways, from engaging in the normative practitioner literature to schools contracting with outside service providers and technical support. In what follows, we describe a case study of the first steps of a partnership-based approach where we as researchers set out to explore the ways in which a formal research-practice partnership could address the needs of practitioners in schools around working with large, complex datasets (Coburn \& Penuel, 2016; Penuel, Allen, Coburn, \& Farrell, 2015; Penuel et al., 2020), with the specific focus here on the case of focusing on the often unexamined step of filtering, organizing, and visualizing the data to make it accessible for decision making by school leaders. Coburn, Penuel, and Giel (2013) define researchpractice partnerships (RPPs) as "long-term collaborations, which are organized to investigate problems of practice and generate solutions for improving district outcomes" (p. 1). Under this general definition, these authors identified five common characteristics across the partnerships they studied: "(1) longterm; (2) focused on problems of practice; (3) committed to mutualism; (4) use intentional strategies to foster partnerships; and (5) produce original analyses" (p. 2) (Coburn, Penuel, \& Geil, 2013). For the partnership described in the present study, we initially framed these five characteristics as inputs into what makes a typical project a partnership. Using these characteristics as proximal goals, along with building on the work of others (Bryk et al., 2010; Cohen-Vogel et al., 2015), we viewed this partnership not only as an opportunity to support practitioners gaining novel insights on their learners using previously unexplored data, but we also saw it as an opportunity to begin providing case-based examples of what it means to engage in collaborative data-intensive improvement and education leadership data analytics for the growing field of educational data science.

\section{Partnership context}

At the start of the partnership, we analyzed data from 5 high schools in the CMO, with total enrollment of approximately 1,500 students. Students in grades 9-12 were 12\% Asian, 3\% Black, 55\% Hispanic, 23\% White, and 5\% Multiracial and 43\% of students qualified for free or reduced priced lunch. The purpose of the partnership was twofold: (1) support the CMO's 
use of data from multiple digital platforms as a resource for improvement and (2) use theory and prior research to develop partnership activities in order to learn about collaborative dataintensive improvement and education leadership data analytics. To meet these twofold aims, we used a design-based research approach (Cobb, Confrey, diSessa, Lehrer, \& Schauble, 2003) to, as Dede (2004) notes, "introduce evocative, theoryinfluenced designs, then draw out implications for new theoretical ontologies of phenomena" (p.111) (Dede, 2004), to develop what Coburn and Turner (2011) refer to as "data use interventions." As outlined in relation to our theory of action, we set out to intervene on step 2 of Figure 1 - organize, filter, and analyze data originating from a common LMS - and produce data products that were intended to support educational leaders' understanding of students' actions in the LMS in order to identify opportunities to improve. Our analyses centered on 910th grade students across multiple subject areas. The CMO was in the process of developing an instructional model that privileged not only how well students did on specific assessments but what they did in terms of strategies and behaviors, such as how students used the assessment system, for example the number of times a student may opt to retake summative assessments within the LMS. An organizing idea for the partnership, therefore, centered on researchers wrangling data, developing data visualizations, and jointly interpreting data products with practitioners. CMO leaders expressed particular interest in Algebra I around which we analyzed data for $n=476$ students. In what follows we briefly describe our analytical approach for the central data product used early on in the partnership and then describe our approach for analyzing educational leaders' reactions to the data products using a qualitative case study design.

\section{Data Product Development}

An early meeting in the partnership highlighted the importance of students' assessment taking within the LMS. Courses in the CMO were structured around self-directed learning where students accessed digital resources and completed assessments all within a common LMS. Given the freedom and choice offered to students, a core interest of the CMO was students' assessment taking patterns in Algebra I (e.g., When do students take them? In what order do students take them? How successful are students?). Thus, the CMO's instructional model created the potential for high degrees of variation in what students did as they worked to complete assessments in the LMS. To model this variation, we used agglomerative hierarchical cluster analysis (HCA) techniques combined with a heatmap visualization. This approach had multiple benefits. As a technique, which we describe in more detail below, it does little summarization of data; instead the algorithm and chosen visualization approach groups, or clusters, observations (i.e., students) based on the available data for a student. For this first analysis, and based on joint problem and priority definitions between members of the partnership, we set out to understand students' assessment taking patterns within the LMS. In particular, we focused on $9^{\text {th }}$ grade data across the CMO, including data from $n=476$ students in Algebra I. We focus on the number of attempts per student across nine sub-sections within Algebra I. Assessment taking was a key open question to CMO leaders because of the selfdirected nature of math instruction and how this goal was translated into policies where students could take assessments as many times as they like until they pass the exam. To best understand the HCA patterns, we also included students' final grade in Algebra I for each student.

HCA heatmaps are an emerging method in education data science (Bowers, 2021) for visualizing individual student data patterns, clustered and visualized in such a way that each student's information is retained (to avoid averaging all students to a single number or best fit line), yet providing the ability to compare similar student data patterns and outcomes together (Bowers, Zhao, \& Ho, in submission). For a review of cluster analysis methods in education see (Alfredo, Félix, \& Àngela, 2010; Bowers, 2007, 2010). Here we draw on the literature on visual data analytics in education (Bienkowski et al., 2012; Johnson, Levine, Smith, \& Stone, 2010) to inform step 2 of the data use cycle of filter, organize, analyze, and now here visualize using visual data analysis, which along with education data mining and learning analytics "have the potential to make visible data that have heretofore gone unseen, unnoticed, and therefore unactionable" (p.ix) (Bienkowski et al., 2012). Visual data analysis "blends... computational methods with sophisticated graphics engines to tap the ability of humans to see patterns and structure in complex visual presentations (Johnson et al., 2010). Visual data analysis is designed to help expose patterns, trends, and exceptions in very large heterogeneous and dynamic datasets collected from complex systems" (p.15) (Bienkowski et al., 2012), which we draw on here as a means to organize, filter, analyze, and visualize the data in an effort to help educators identify "novel insights and unexpected patterns and correlations in their data" (p.15) (Selwyn et al., 2021).

As a form of visual data analysis (Johnson et al., 2010; Keim, Mansmann, Schneidewind, \& Ziegler, 2006), HCA heatmaps are a form of data mining and descriptive analysis in which similar data patterns of students (rows) are matched together across columns of data features (here assessment attempts) and placed next to each other through hierarchical cluster pattern analysis (Bowers, 2010; Gu, Eils, \& Schlesner, 2016; Wilkinson \& Friendly, 2009). A "heatmap" was then generated to display the data for each student row across all nine assessments, whereby low or no attempts are represented by white, and ranging up through grey to black which represents a high number of attempts by a student for that summative assessment (as will be discussed later on, missing data was meaningful). To improve interpretability, we square root transformed the number of assessment attempts per student for each summative assessment. Similarity of clusters of student data are then represented with a cluster tree, i.e., dendrogram, in which longer horizontal lines indicates more dissimilar data patterns. Following recommendations from the literature on cluster analysis in education (Bowers, 2010; Bowers et al., in submission; Jorion et 
al., 2020; Lee, Recker, Bowers, \& Yuan, 2016), we used Euclidean distance as the distance metric and average linkage as the agglomeration method in the $\mathrm{R}$ statistical package, including gplots and heatmap.2 (R Development Core Team, 2019; Warnes et al., 2020).

\section{METHODS:}

This section describes the case study data and our analytical approach for understanding two meetings where researchers and practitioners came together to make sense of and make plans based on the heatmap described above. Our analysis of practitioners' sensemaking is organized around two research questions:

1) In what ways can an RPP support educational leaders' use of new and complex datasets to inform improvement cycles?

2) How do educational leaders make sense of data products that are built on complex LMS datasets meant to inform step 2 of the data use cycle?

These two questions address practitioners' reaction to the partnership and how the multidimensional nature of the partnership (e.g., data wrangling, visualization, and joint sensemaking) helped CMO leaders identify opportunities to improve.

For this study we drew on qualitative case study design (Yin, 2017) informed by the design-based research literature. As noted across this literature, design-based research is "(a) pragmatic (i.e. design-oriented and intervention-oriented); (b) grounded in theory and research; (c) interactive, iterative and flexible; (d) integrative; and (e) contextual" (p.37) (Reimann, 2011). As our focus is on the interactive collaborative work around a specific data visualization (the HCA heatmap), the focus of our data collection was a case study examining the meeting discourse across two meetings in which the data visualization was discussed. As Goodwin (1994) notes:

The ability to build and interpret a material cognitive artifact... is embedded within a web of socially articulated discourse. Talk between coworkers, the lines they are drawing, measurement tools, and the ability to see relevant events... all mutually inform each other within a single coherent activity. Simultaneously, the practices clustered around the production, distribution, and interpretation of such representations provide the material and cognitive infrastructure that make... theory possible. (p.626) (Goodwin, 1994).

Given this perspective, our data for the case study was limited to the discourse across meetings that included CMO leaders and researchers, focusing on the HCA heatmap as the artifact. Meeting participants for the two meetings outlined in this study included four researchers and two CMO leaders in the first meeting and one leader in the second meeting. A previous meeting where data were outlined and research questions surfaced included seven CMO leaders, including the CEO, head of academics, and technology/information leads. Follow-on meetings included a consistent group of three CMO leaders and expanded as needed to involve groups of teachers and members of the CMO technology and information teams.

Each meeting was audio recorded and transcribed, then combined with field notes that were collected by participating researchers. Data analysis for the case study drew on the research literature to guide our selection of an initial round of deductive codes to focus on the second step of the data use theory of action noted above, including organize, filter, analyze, visualize, understanding, expertise, collaboration, and information-to-knowledge generation, along with emergent codes of connection, application, exploration, and surprise. Each coded passage was discussed by the researchers, and we combined this analysis with analytic memos written by the researchers, examining similarities, differences, and patterns across the data (Miles \& Huberman, 1994).

\section{ANALYSIS:}

Figure 2 is the data product that was central to the two meetings that we examine in depth, below. We draw attention to this figure because, as we argue, it played a central role in generating subsequent opportunities for improvement discussed in two meetings. Moreover, Figure 2 is a concrete outcome of what we mean by focusing on step 2 - organize, filter, and analyze - from the data use theory of action presented earlier. At the start of the partnership, the CMO was in the early years of its efforts to rethink and redesign teaching and learning across the CMO, and integrating various technologies was central to their vision for achieving quality instruction. The newness of the LMS and the accompanying data meant that the partnership was a direct infusion of support in making sense of newly available data. Beyond providing technical assistance in wrangling LMS data, we as researchers also facilitated meetings where members of the partnership discussed research questions and priorities as well as jointly interpreted data products with CMO leaders and teachers. Later partnership activities included professional development sessions, just-in-time data analyses, and continued efforts to organize, filter, and analyze data from changing digital learning environments. The routines that were established in the development of Figure 2 were continually refined over of the life of the partnership in line with our evolving Data Use Theory of Action. For the analysis and meetings discussed in this paper, researchers in the partnership used the general idea of "clustering students based on assessment" to organize and filter data. Much of the data that was available within the LMS was initially ignored by the CMO, such as students' accessing of learning resources. The focus on assessment taking, general idea of clustering, and the emphasis on Algebra I helped to shape the joint sensemaking meetings. 

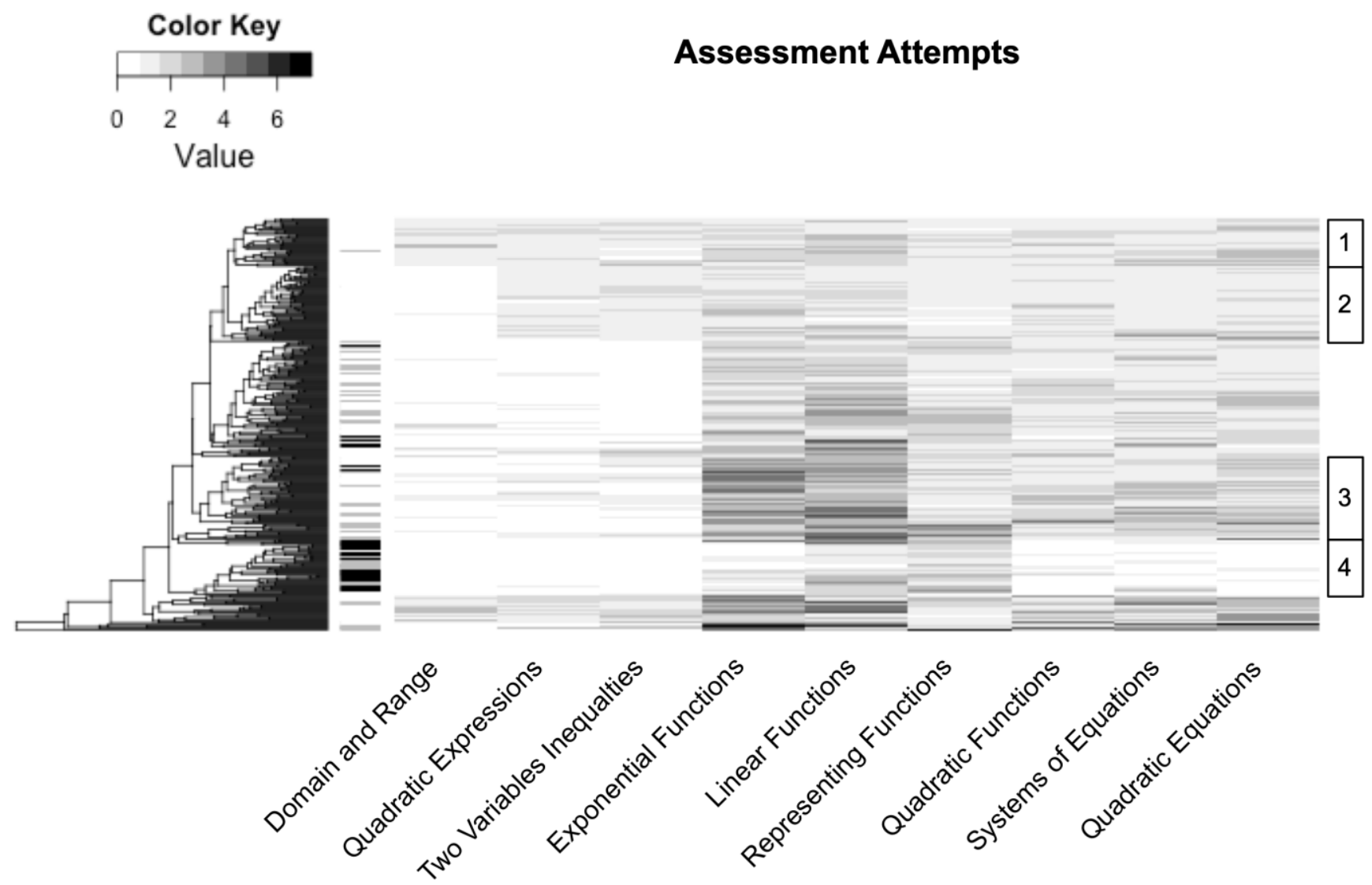

Assessments

Figure 2: Hierarchical Cluster Analysis Heatmap of Student Algebra I Sub-Section Summative Assessments and Course Grades. The standardized number of summative assessment attempts for each student (rows) for each course sub-section in $9^{\text {th }}$ grade Algebra I (columns) is represented by a color block, ranging from white (zero attempts) to black (many attempts). The similarity or dissimilarity of student assessment attempt pattern is represented on the far left by the cluster tree, with shorter horizontal lines indicating more similar patterns, while longer horizontal lines indicate dissimilarity. Final course grade with similar color coding, from darker (lower grades) to lighter (higher grades) is represented between the heatmap and the cluster tree. Of note, the majority of students clustered into the five top clusters, with different patterns of summative assessment attempts associated with different grades. Four clusters are denoted by the numbered boxes on the right, with clusters 1 and 2 representing moderate levels of summative assessment attempts and the highest grades while cluster 3 represents high numbers of attempts with moderate to low grades, and cluster four represents the cluster of lowest number of attempts (note the lighter pattern across the heatmap) with the lowest grades. Across the assessments columns, students made the most attempts in Exponential Functions and Linear Functions (darker columns) with the least attempts in Domain and Range, Quadratic Expression and Two Variable Inequalities (lighter columns). 
Hierarchical Cluster Analysis Heatmap of Student Algebra I Summative Assessment Attempts

In Figure 2, the nine assessments that comprised Algebra I are displayed as columns: 1) Domain and Range, 2) Quadratic Expressions, 3) Two Variable Inequalities, 4) Exponential Functions, 5) Linear Functions, 6) Representing Functions, 7) Quadratic Functions, 8) Systems of Equations, and 9) Quadratic Equations. Each row in the heatmap represents one of 476 students. The intersection of student and assessment is represented by color coded cells where lighter colors denote few attempts and darker colors denote more attempts per student and assessment. The agglomerative hierarchical cluster analysis algorithm ordered students, such that individual rows with similar assessment-taking patterns are next to each other. Similarity and dissimilarity of student patterns is represented by a cluster tree, or dendrogram, in which longer horizontal lines represent greater dissimilarity. Lastly, final course grade in Algebra I for each student is represented by light (higher grade) to dark (lower grade) for each row in the column between the cluster tree and the summative assessment heatmap in Figure 2.

Clusters of interest are denoted by 1, 2, 3 or 4 on the far right of the cluster analysis heatmap (Figure 2, right). Cluster 1 is comprised of students who have a consistently high number of assessment attempts across all Algebra I modules, and they receive the high grades. Cluster 2 is very similar to Cluster 1 (note proximity in the row order of the two clusters, and similarity denoted by the cluster tree). Cluster 2 differs from Cluster 1 in that for Cluster 2, these students appear to have similar patterns of assessment attempts across all of the modules except the first "Domain and Range" module. For this module, Cluster 2 students have a very low number of summative assessment attempts. All of the Cluster 2 students received the highest grade for the course. In contrast, Cluster 3 students have a low number of attempts for the first three modules of Domain and Range, Quadratic Expressions, and Two Variable Inequalities, a very high number of attempts for Exponential Functions and Linear Functions (darkest in the heatmap) and somewhat higher number of attempts for the other modules. Many of these students receive a low grade for the course. And finally, Cluster 4 students have the lowest grades, and have the least number of summative assessment attempts across all modules (Figure 2: lighter cells in the heatmap left to right). Thus, while for Domain and Range, Clusters 2 and 4 have similar data patterns for the number of assessment attempts, these patterns are very different from each other once all of the rest of the data for Algebra I summative assessment attempts is included across all modules. Of note, when examining the pattern of data across the columns (Figure 2, columns), it is evident that overall the least number of summative assessment attempts are in the first three modules on the left of Figure 2 (lighter color on the heatmap), while the greatest number of attempts overall are by far in Exponential Functions and Linear Functions (darkest color on the heatmap).
Informing the Data Use Theory of Action - Data to Information to Knowledge:

The development of Figure 2 represents a core way in which researchers in the partnership supported CMO leaders. To create it, researchers worked with data the CMO had not analyzed before and developed a visualization that communicated patterns across student behaviors and choices. Early in the year, we met with the school leadership team to receive feedback on the visualization in Figure 2 and provided them with an opportunity to delve into the data and identify opportunities for organizational and instructional improvement.

After providing an overview of the figure, the school leaders had the following impressions. One of the network leaders noted when asked what they see in the heatmap and if it makes sense: "So first thoughts, it totally makes sense that some [students] have more [attempts] than others". He went on to note the specifics in the heatmap in an exchange with the data analyst:

CMO Leader: So do we have a different number of attempts... I'm really super intrigued by there's a lot of white. That means that they've never took it... And then yes, I guess I didn't expect there to be any two students who were exact. I think students [in cluster 1] makes it like we're pretty darn close, if I look in the shadings, right? Those are probably... kids who were doing pretty well in the class overall, yes?

Analyst: $\quad$ Few attempts and high grades

CMO Leader: So I'm looking at like Systems of Equations [on the heatmap in Figure 2]. Linear Functions have a much higher number [of attempts] than Quadratics...if the Quadratics is the hardest part of the Algebra piece, you're going to have less people even taking it.

Throughout this quote, this CMO leader is able to use the visualization to see the patterns and relationships in the data. Within the context of a joint interpretation session, this particular visualization allowed the leader to ask questions of researchers in real-time. Furthermore, in this quote, the CMO leader notes that he is "intrigued" and immediately sees that because there is a lot of white in the figure versus darker cells, there are interesting differences and patterns across students and assessments in Algebra I. Later on in the meeting, the CMO leader discusses an unexpected result from Figure 2:

What is fascinating to me on this is a couple of thoughts: One general takeaway is not all assessments are created equal, even though we treat them that way. It is so clear, if you had your year broken into nine chunks of time [like in Figure 2] that the two in the middle need more time [Exponential Functions and Linear Functions], like the tests are harder... So we 
could smooth them out or figure out how to represent that those weigh more. They should have more weight on the way we think about helping a kid go through this.

Through this quote, this CMO leader sees something unexpected, and through the visualization of students' data, the row by column patterns show that two modules of the year-long curriculum are much more difficult for students than other modules, as evidenced by the higher rates of taking and retaking of the assessment. This prompts the leader to wonder if either more time or more score weighting should be applied to those two specific modules of the curriculum - an idea that leads directly from the visualization. This leader continues by stating that:

[Second] the Linear Functions thing is much harder and those are the ones we haven't done. So that's in the design question [of Figure 2].... if we took out the two hardest [columns in the heatmap], do we still have groups [of kids by rows] kind of clustered the way we've got, or would those clusters sort of smoosh close? Because the things that I'm wondering about are there literally key, specific points in an individual course that are the differentiators, that are one test is causing 25 kids to not pass it?

Note in this next quote, the leader then turns back to the analyst, and generates ideas for restructuring the figure, to ask new questions that are of interest to the school in an effort to find solutions for specific students on specific curriculum modules and assessments. The visualization helps the practitioner rework the problem of practice, and turn the question back to the data analysts. This move points to an important takeaway from the partnership approach attempted in this project: joint data interpretation meetings matter. By this, and in the language of Coburn and Turner (2011), this meeting is an important point of intervention. In this meeting with the support of analysts, practitioners were helped in making sense of the visualization and scaffolded toward principled takeaways. Importantly, for the analysts, many of the subtleties in the data patterns could not have been disentangled absent the practitioners.

The central concern of this study is the role of the partnership in filtering, organizing and analyzing data. Given the unique complexities of the data, both researchers and CMO leaders were needed to make sense of the CMO's LMS data. CMO leaders provided direction on what questions to ask. Researchers provided expertise on how to wrangle, analyze, and visualize data using hierarchical cluster analysis with a heatmap visualization. Leaders provided necessary context for ensuring proper interpretation of students' actions represented in the visualization, and researchers provided necessary context for interpreting the visualization itself. Importantly, participating researchers did not draw conclusions from the visualization and report these to the CMO leaders. Rather, the CMO leaders drew their own inferences and conclusions and communicated these back to the researchers in a way that promoted joint sensemaking.

Informing the Data Use Theory of Action - Combining Understanding with Expertise:

As noted throughout this study, our goal was to understand how a partnership between researchers and practitioners could turn new and novel data sources into information and knowledge. To this end, detailing an entire sequence through the full data use cycle in Figure 1 is outside the scope of the present study. However, to provide an indication of where the CMO would go next, at a subsequent follow-up meeting that was explicitly structured to reflect on the process and utility of the presented data product, one of the other CMO leaders reflected on the previous discussion from above and noted that they had sent a web-based version of the figure to other leaders in the CMO.

And so they were looking at it and I think they came away at least with the Algebra piece that they kind of confirmed for them what they were thinking of Linear Functions and Quadratics. They've kind of been hearing that that was an issue, so it's been good confirmation for them.

As the leader observes, the data product had a confirmatory function related to some assessments.

And so currently... our course level teams go through and look through the different focus areas and assessments and try to determine which ones are too hard to too easy... This [the Figure 2 discussion] is I think leaps and bounds beyond that in terms of looking at over the course of this focus area [of Algebra I] what are the patterns that we see. What are different focus areas within each course that seem to be having the most difficulty and what are the different things that we can do to address that?... Or is it at the same difficulty level as other assessments?

I think that this [the Figure 2 discussion] just opened up a huge frame of conversation for us to have with course level teams and provide them data that I think they'll be able to dig deep on and start to revise a lot of these courses...Like when [the other leader] was talking about let's remove Exponential Functions and Linear Functions and see how the segments look differently then, I think without fully having that explanation from you guys in the first place we wouldn't have come to those types of realizations.

It was a totally different way of visualizing data that I think we haven't seen before... It was just a really, really interesting way to think about data. Because we think about it in simpler terms here and so it's nice to see the larger possibilities with what we can do with the data that we have. 
Thus, this leader's reflection on the discussion shows the utility of both the researchers and the practitioners coming together to collaboratively address the problems of practice in the organization.

In reflecting on the data product, the leader noted that in addition to the ways in which it supported efforts to reevaluate different assessments, it also had an at the time unanticipated partnershipbuilding effect:

\section{I think it was also illuminating for us to kind of see the kind of analyses that you guys can do and just put a little more understanding on our part on where we can go with some of this data.}

The success of this data product was seemingly an important step in building trust within the partnership, such as demonstrating competency and follow-through, similar to building trust within schools (Bryk \& Schneider, 2002). The joint interpretation meeting was a trust building activity through the ways in which having multiple researchers present helped in setting up and interpreting the focal data product, as noted by one of the school leaders at the second meeting:

\section{I think we really appreciated the ramp up for this visualization and I think the amount of time you guys put into it was totally appropriate because just understanding it allows us to dive into it a lot deeper and also to think about what are other additions and subtractions that we can make from it. Whereas if we had a more cursory understanding I don't think we could have got it.}

The work of the partnership takes shape across these quotes. While as researchers we focused on a concrete problem of helping the $\mathrm{CMO}$ organize, filter, analyze, and visualize new and novel data, our efforts to understand the partnership itself, through a reflexive analysis of meeting notes and transcripts, helped in elaborating the ways in which the data product and the meeting in which it was discussed-along with critical pre-work activities of jointly surfacing research questions - all helped in translating LMS data into a resource for improvement, namely for rethinking and reevaluating assessments in Algebra I.

\section{DISCUSSION:}

The purpose of this paper was to describe the process of a collaborative researcher-practitioner partnership focusing on step 2 of the data use theory of action of organize, filter, analyze, and here visualize the data for educator decision making, supporting leaders in the partnering CMO through wrangling and visualizing large and complex datasets. Our findings are potentially significant in three main ways. First, this study provides a novel use of hierarchical cluster analysis heatmaps in education for visualizing digital learning environment data, through the use of visual data analytics in education research (Bienkowski et al., 2012; Bowers et al., 2019; Bowers et al., in submission; Johnson et al., 2010; Lee et al., 2016). Second, this study is one of the first to dive deeply into step 2 of the data use theory of action (Figure 1), in which all of the other steps have received significant attention in the research. Third, our case study provides an example that can inform future research related to collaborative meetings that are intended to support researchers and CMO leaders jointly identifying instructional improvement opportunities using complex data from digital learning environments. Generating the next steps to plan for instructional improvement required the unique skills and expertise of both researchers and practitioners. Thus, through this study, we provide an example of applying educational data science to addressing pressing problems of practice. Our hope is that this study can help spur further research at the intersection of researcher-practitioner partnerships and the application of educational data science.

In describing how CMO leaders reacted to the focal data product, our intent is not to make any claim that this type of data analytic partnership "works" in the sense that it may cause leader and teacher instructional improvement. Rather, through describing the initial steps of working with school practitioners, our goal is to provide examples of how researchers and practitioners could work together to turn data into useful information for knowledge generation. Given the recent sobering research that has indicated that step 2 of the data use cycle may be a problematic sticking point for many schools (Farley-Ripple et al., 2021; Selwyn et al., 2021; Wayman et al., 2017), our results highlight how data science workflows (Agasisti \& Bowers, 2017; Krumm et al., 2018) can be integrated into current ongoing improvement cycles within a school or district to help address the needs of practitioners. It is our contention that collaborative educational data science (Agasisti \& Bowers, 2017; Bowers, 2017; Bowers et al., 2019; Piety, 2019; Piety et al., 2014) can and should be included within the logic model of data use in schools.

\section{The Application of Educational Data Science to the Data use} Theory of Action:

Our results provide evidence for the role of data science to inform the data use theory of action. As noted in Schutt and O'Neil (2013), a data scientist is someone who brings together visualization and data sense, and communicates results to stakeholders in ways that help specific audiences derive actionable next steps. This work includes the traditional work of collecting data, processing the data, cleaning the data, and then using exploratory data analysis, but then also includes data mining, pattern analysis, visualization, reporting the findings, and building data products that then can inform decision making (Schutt \& O'Neil, 2013). 


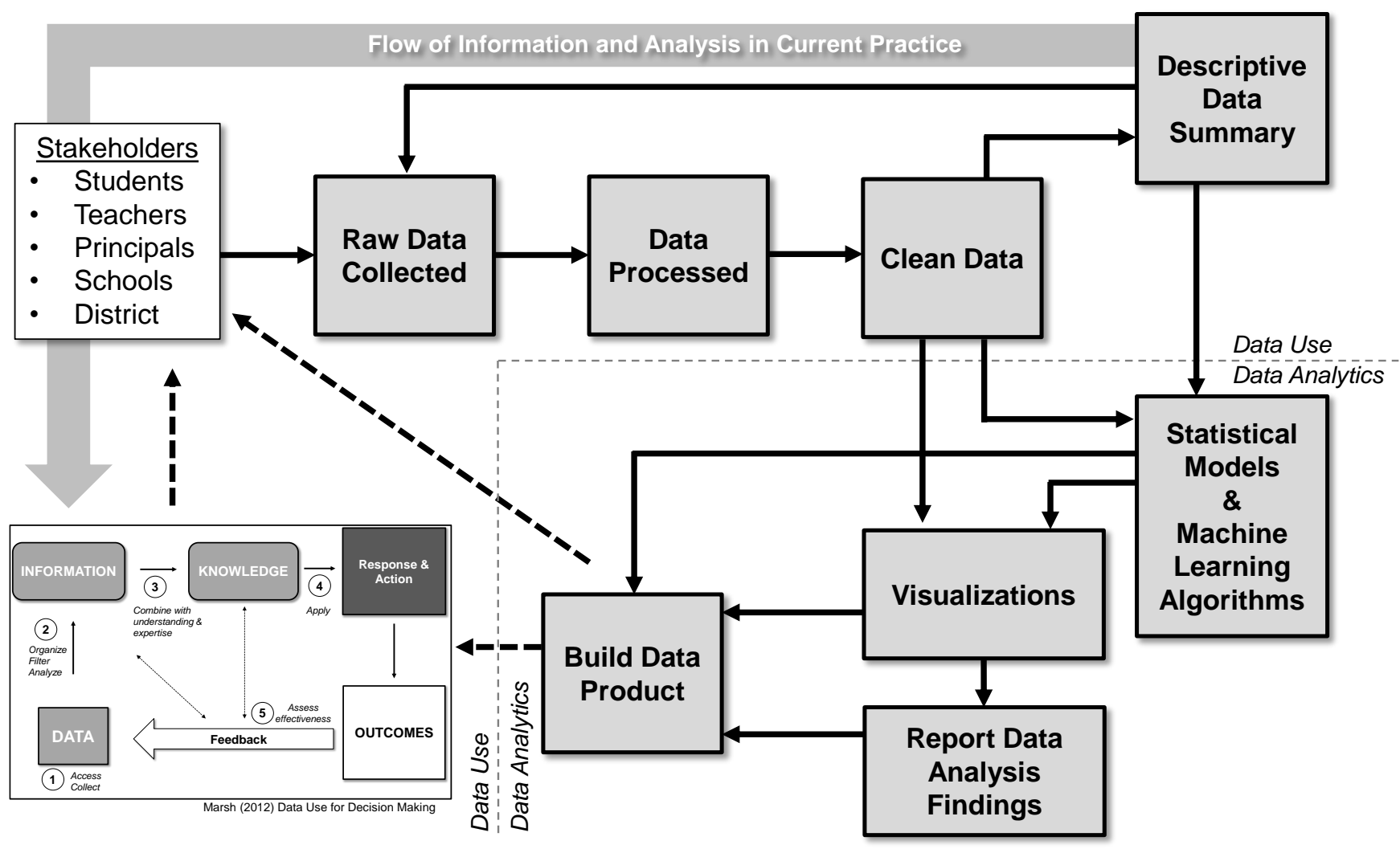

Figure 3: Combined Logic Model of Data Analytics for Decision Making in Schools. Adapted from Schutt \& O’Neil (2013) and Marsh (2012).

Drawing on our results, in Figure 3 we adapt the logic model of data science from Schutt and O'Neil (2013) in combination with the data use theory of action to propose a combined logic model of how educational data science can support decision making in schools. The logic model starts on the upper left of Figure 3 with the school stakeholders of students, teachers, principals, schools, and districts. Then proceeding to the right, schools collect raw data, and process and clean that data (Figure 3, top). As noted in the literature on data use in schools, teachers and principals are encouraged to use descriptive data summaries (Figure 3, top right) that feed back to the stakeholders (Farrell, 2014; Schildkamp \& Poortman, 2015; Schildkamp et al., 2016) and inform the data use theory of action (Figure 3, bottom left). As noted by the grey arrow at the top of Figure 3, descriptive data summaries are intended to inform all five steps of the data use theory of action from Figure 1. Thus, the top section of Figure 3 illustrates a non-trivial amount of work (Selwyn et al., in press) that takes specific training in schools related to collecting raw data, processing it, cleaning it, and then creating descriptive data summaries (Bowers, 2017; Bowers et al., 2019; Bruno \& Fox, 1973).

However, a currently unaddressed issue in much of the existing literature is the role of data analytics. Yet, the use of data analytics to help visualize and inform decision making in organizations, such as the use of a visual data analytics HCA heatmap used in this study, has been extensively discussed in the data science literature (Donoho, 2015; Gandomi \& Haider, 2015; Schutt \& O'Neil, 2013). Indeed, this work corresponds with the longstanding work in the domain of Exploratory Data Analysis (EDA) (Tukey, 1962, 1977) in which EDA practitioners work to "address the broad question of "what is going on here?" [with] an emphasis on graphic representations of data... [in which] the goal of EDA is to discover patterns in data." (p.132) (Behrens, 1997). Through data science practices, data analytics provides a means to leverage the potential of current data systems in schools through additional useful analyses while also translating the findings into useful data products for teachers and administrators (Agasisti \& Bowers, 2017; Bowers, 2017, 2021; Bowers et al., 2019; Dimitriadis, Martínez-Maldonado, \& Wiley, 2021; Fischer et al., 2020; Krumm et al., 2018; Siemens, 2013), which can then inform each step of the data use theory of action. In Figure 3, we denote the dotted line between the domains of Data Use and Data Analytics to draw the distinction in the data science process from descriptive data summaries, such as those described earlier in Selwyn et al. (2021), to data analytics which includes statistical models, machine learning, visualizations, reporting findings, and building data products (Figure 3, bottom right). This information then flows back into informing both the stakeholders directly and the data use theory of action (Figure 3, 
dashed arrows). Thus, drawing from our results and our synthesis of the literature, this process can inform each step of the data use theory of action, but first mirrors the current literature in the need to collect, process, and clean the data and generate descriptive summaries. The additional domain of data analytics in Figure 3 provides the opportunity for the educational data scientist to use data mining and visual data analytics to bring to light previously unknown patterns and relationships in the data.

\section{The Use of Visual Data Analytics in Education Research:}

A core benefit of the application of pattern analysis, data mining, and visualization, is the ability of these new forms of analytics from the data sciences and learning analytics domains to help surface patterns in the data that were previously unobserved, unknown and unactionable (Agasisti \& Bowers, 2017; R. S. Baker \& Inventado, 2014; Bienkowski et al., 2012; Fischer et al., 2020; Siemens, 2013). The partnership described in this study demonstrates the usefulness of a HCA heatmap visualization and replicates and extends the emerging literature in education on these types of visualizations (Bowers, 2007, 2010; Bowers et al., in submission), especially with data from digital learning environments (Hawn, 2019; Jorion et al., 2020; Krumm et al., 2018; Lee et al., 2016; Nitkin, 2018). Rather than replace traditional exploratory data analysis and inferential regressionbased statistics, this type of analysis is a powerful way of describing multidimensional datasets in ways that support novel insights. Recently termed quantitative phenomenology (Bowers, Blitz, Modest, Salisbury, \& Halverson, 2017), rather than attempt to generalize to the population mean, which is the central concept in inferential statistics, data analytics of the type described in this paper are focused on providing a rich and thick description of a specific phenomenon occurring in schools. Rather than summarize all students to averages and best fit regression lines, HCA heatmap visualizations provide a view on an entire dataset, patterning the data for each student for each data point, in a way in which the human eye can visualize and interpret the patterns in the data (Bowers, 2010; Bowers et al., in submission; Eisen, Spellman, Brown, \& Botstein, 1998). While the visualization depends on many dimensions, these types of techniques can provide a helpful means of visualizing and describing high dimensionality education datasets, while keeping the individual student as the unit of analysis.

\section{CONCLUSION:}

Data, such as formative assessment results are increasing in volume and variety across schools due to the increasing use of digital learning environments and administrative data systems. This change in school data has increased the importance of filtering, organizing, and analyzing data. In these early days of the data revolution in education, partnerships between researchers and practitioners that draw on the skills and expertise of each, hold the potential for turning these complex data sources into resources for school and instructional improvement.
The partnership described in this paper demonstrates how practitioner-driven questions, researchers' abilities to manipulate and visualize data, and structured collaborative activities can support the sensemaking of both researchers and practitioners. In the short term, these kinds of collaborations can help to build the case for school practitioners to integrate complex data sources into their decision making. In the long term, it is hoped that increasingly capable schools and technological tools will make the kinds of explorations described in this paper more common place.

\section{Citation:}

Bowers, A.J., Krumm, A.E. (2021) Supporting Evidence-Based Improvement Cycles Through a Data-Intensive Partnership. Information and Learning Sciences, 122(9/10) 629-650. https://doi.org/10.1108/ILS-09-2020-0212

\section{References:}

Agasisti, T., \& Bowers, A. J. (2017). Data Analytics and Decision-Making in Education: Towards the Educational Data Scientist as a Key Actor in Schools and Higher Education Institutions. In G. Johnes, J. Johnes, T. Agasisti, \& L. López-Torres (Eds.), Handbook on the Economics of Education (pp. 184-210). Cheltenham, UK: Edward Elgar Publishing. https://doi.org/10.7916/D8PR95T2

Aleven, V., Roll, I., McLaren, B. M., \& Koedinger, K. R. (2016). Help Helps, But Only So Much: Research on Help Seeking with Intelligent Tutoring Systems. International Journal of Artificial Intelligence in Education, 26(1), 205223. doi:10.1007/s40593-015-0089-1

Alfredo, V., Félix, C., \& Àngela, N. (2010). Clustering Educational Data. In C. Romero, S. Ventura, M. Pechenizkiy, \& R. S. J. d. Baker (Eds.), Handbook of Educational Data Mining (pp. 75-92). Boca Raton, FL: CRC Press.

Baker, R. S., Corbett, A. T., Koedinger, K. R., \& Wagner, A. Z. (2004). Off-task behavior in the cognitive tutor classroom: when students "game the system". Paper presented at the Proceedings of the SIGCHI Conference on Human Factors in Computing Systems, Vienna, Austria. https://doi.org/10.1145/985692.985741

Baker, R. S., \& Inventado, P. S. (2014). Educational data mining and learning analytics. In J. A. Larusson \& B. White (Eds.), Learning Analytics (pp. 61-75). Retrieved from http://link.springer.com/chapter/10.1007\%2F978-1-46143305-7_4

Baker, R. S. J. d., Corbett, A. T., Koedinger, K. R., Evenson, S., Roll, I., Wagner, A. Z., . . Beck, J. E. (2006). Adapting to When Students Game an Intelligent Tutoring System, Berlin, Heidelberg.

Bambrick-Santoyo, P. (2010). Driven by Data: A Practical Guide to Improve Instruction. San Francisco, CA: JosseyBass.

Beck, J. E., \& Gong, Y. (2013). Wheel-Spinning: Students Who Fail to Master a Skill, Berlin, Heidelberg. 
Behrens, J. T. (1997). Principles and procedures of exploratory data analysis. Psychological Methods, 2(2), 131-160. doi:10.1037/1082-989X.2.2.131

Bernhardt, V. (2013). Data analysis for continuous school improvement ( 3 ed.). New York: Routledge.

Bienkowski, M., Feng, M., \& Means, B. (2012). Enhancing Teaching and Learning Through Educational Data Mining and Learning Analytics: An Issue Brief. Retrieved from Washington, DC: http://www.ed.gov/edblogs/technology/files/2012/03/edmla-brief.pdf

Boudett, K. P., City, E. A., \& Murnane, R. J. (2013). Data Wise: Revised and Expanded Edition: A Step-by-Step Guide to Using Assessment Results to Improve Teaching and Learning. Revised and Expanded Edition. Cambridge, MA: Harvard Education Press.

Bowers, A. J. (2007). Grades and data driven decision making: Issues of variance and student patterns. (Ph.D.). Michigan State University, East Lansing.

Bowers, A. J. (2009). Reconsidering grades as data for decision making: More than just academic knowledge. Journal of Educational Administration, 47(5), 609-629. doi:10.1108/09578230910981080

Bowers, A. J. (2010). Analyzing the longitudinal K-12 grading histories of entire cohorts of students: Grades, data driven decision making, dropping out and hierarchical cluster analysis. Practical Assessment Research and Evaluation, 15(7), 1-18. Retrieved from http://pareonline.net/pdf/v15n7.pdf

Bowers, A. J. (2017). Quantitative Research Methods Training in Education Leadership and Administration Preparation Programs as Disciplined Inquiry for Building School Improvement Capacity. Journal of Research on Leadership Education, 12(1), 72 - 96. doi:10.1177/1942775116659462

Bowers, A.J. (2021) Early Warning Systems and Indicators of Dropping Out of Upper Secondary School: The Emerging Role of Digital Technologies. OECD Digital Education Outlook 2021: Pushing the Frontiers with Artificial Intelligence, Blockchain and Robots, Chapter 9, p.173-194. OECD Publishing, Paris. https://doi.org/10.1787/589b283f$\underline{\text { en }}$

Bowers, A. J., Bang, A., Pan, Y., \& Graves, K. E. (2019). Education Leadership Data Analytics (ELDA): A White Paper Report on the 2018 ELDA Summit. https://doi.org/10.7916/d8-31a0-pt97.

Bowers, A. J., Blitz, M., Modest, M., Salisbury, J., \& Halverson, R. (2017). Is There a Typology of Teacher and Leader Responders to CALL, and Do They Cluster in Different Types of Schools? A Two-Level Latent Class Analysis of CALL Survey Data. Teachers College Record, 119, 1-66. Retrieved from http://www.tcrecord.org/Content.asp?ContentId=21677

Bowers, A. J., Shoho, A. R., \& Barnett, B. G. (2014). Considering the Use of Data by School Leaders for Decision Making. In A. J. Bowers, A. R. Shoho, \& B. G. Barnett (Eds.), Using Data in Schools to Inform Leadership and
Decision Making (pp. 1-16). Charlotte, NC: Information Age Publishing. http://dx.doi.org/10.7916/D8862F32

Bowers, A. J., Zhao, Y., \& Ho, E. (in submission). Towards Hierarchical Cluster Analysis Heatmaps as Visual Data Analysis of Entire Student Cohort Longitudinal Trajectories.

Bruno, J. E., \& Fox, J. N. (1973). Quantitative Analysis in Educational Administrator Preparation Programs. Columbus, Ohio: The ERIC Clearinghouse on Educational Management, University Council for Educational Administration.

Bryk, A. S., Gomez, L. M., \& Grunow, A. (2010). Getting Ideas Into Action: Building Networked Improvement Communities in Education. Retrieved from Stanford, CA: http://www.carnegiefoundation.org/elibrary/getting-ideasaction-building-networked-improvement-communities-ineducation

Bryk, A. S., \& Schneider, B. (2002). Trust in Schools: A Core Resource for Improvement. New York: Russell Sage Foundation.

Cho, V., \& Wayman, J. C. (2015). Districts' Efforts for Data Use and Computer Data Systems: The Role of Sensemaking in System Use and Implementation. Teachers College Record, 116(2), 1-45. Retrieved from http://www.tcrecord.org/content.asp?contentid $=17349$

Clow, D. (2014). Data wranglers: human interpreters to help close the feedback loop. Paper presented at the Proceedings of the Fourth International Conference on Learning Analytics And Knowledge, Indianapolis, Indiana, USA. https://doi.org/10.1145/2567574.2567603

Cobb, P., Confrey, J., diSessa, A., Lehrer, R., \& Schauble, L. (2003). Design Experiments in Educational Research. Educational Researcher, 32(1), 9-13. doi:10.3102/0013189x032001009

Cobb, P., \& Jackson, K. (2012). Analyzing Educational Policies: A Learning Design Perspective. Journal of the Learning Sciences, 21(4), 487-521. doi:10.1080/10508406.2011.630849

Coburn, C. E., \& Penuel, W. R. (2016). Research-Practice Partnerships in Education: Outcomes, Dynamics and Open Questions. Educational Researcher, 45(1), 48-54. doi:doi:10.3102/0013189X16631750

Coburn, C. E., Penuel, W. R., \& Geil, K. E. (2013). ResearchPractice Partnerships: A Strategy for Leveraging Research for Educational Improvement in School Districts. Retrieved from New York, NY: http://w.informalscience.org/images/research/ResearchPractice-Partnerships-at-the-District-Level.pdf

Coburn, C. E., \& Turner, E. O. (2011). Research on Data Use: A Framework and Analysis. Measurement: Interdisciplinary Research and Perspectives, 9(4), 173-206. doi:10.1080/15366367.2011.626729

Coburn, C. E., \& Turner, E. O. (2012). The Practice of Data Use: An Introduction. American Journal of Education, 118(2), 99-111. doi:10.1086/663272

Cohen-Vogel, L., Tichnor-Wagner, A., Allen, D., Harrison, C., Kainz, K., Socol, A. R., \& Wang, Q. (2015). Implementing 
Educational Innovations at Scale. Educational Policy, 29(1), 257-277. doi:doi:10.1177/0895904814560886

Cosner, S. (2014). Strengthening Collaborative Practices in Schools: The Need to Cultivate Development Perspectives and Diagnostic Approaches. In A. J. Bowers, A. R. Shoho, \& B. G. Barnett (Eds.), Using Data in Schools to Inform Leadership and Decision Making (pp. 67-95). Charlotte, NC: Information Age Publishing.

Datnow, A., Choi, B., Park, V., \& St. John, E. (2018). Teacher Talk About Student Ability and Achievement in the Era of Data-Driven Decision Making. Teachers College Record, 120(4). http://www.tcrecord.org/Content.asp?ContentId=22039

Dede, C. (2004). If Design-Based Research is the Answer, What is the Question? A Commentary on Collins, Joseph, and Bielaczyc; diSessa and Cobb; and Fishman, Marx, Blumenthal, Krajcik, and Soloway in the JLS Special Issue on Design-Based Research. Journal of the Learning Sciences, 13(1), 105-114. doi:10.1207/s15327809j1s1301_5

DiCerbo, K. E. (2014). Game-Based Assessment of Persistence. Journal of Educational Technology \& Society, 17(1), 17-28. http://www.jstor.org/stable/jeductechsoci.17.1.17

DiCerbo, K. E., \& Kobrin, J. (2016). Communicating assessment results based on learning progressions. Paper presented at the American Education Research Association, Washington, DC.

Dimitriadis, Y., Martínez-Maldonado, R., \& Wiley, K. (2021). Human-Centered Design Principles for Actionable Learning Analytics. Research on E-Learning and ICT in Education: Technological, Pedagogical and Instructional Perspectives, 277-296.

http://martinezmaldonado.net/files/Chapter_31_HumancenteredPrinciples.pdf

Donoho, D. (2015). 50 years of Data Science. Paper presented at the Princeton NJ, Tukey Centennial Workshop.

Eisen, M. B., Spellman, P. T., Brown, P. O., \& Botstein, D. (1998). Cluster analysis and display of genome-wide expression patterns. Proceedings of the National Academy of Sciences, 95, 14863-14868. http://rana.lbl.gov/papers/Eisen_PNAS 1998.pdf

Farley-Ripple, E. N., \& Buttram, J. L. (2015). The Development of Capacity for Data Use: The Role of Teacher Networks in an Elementary School. Teachers College Record, 117(4), 134. http://www.tcrecord.org/Content.asp?ContentId=17852

Farley-Ripple, E. N., Jennings, A., \& Jennings, A. B. (2021). Tools of the trade: a look at educators' use of assessment systems. School Effectiveness and School Improvement, 32(1), 96-117. doi:10.1080/09243453.2020.1777171

Farrell, C. C. (2014). Designing School Systems to Encourage Data Use and Instructional Improvement: A Comparison of School Districts and Charter Management Organizations. Educational Administration Quarterly, 51(3), 438-471. doi:10.1177/0013161x14539806

Fischer, C., Pardos, Z. A., Baker, R. S., Williams, J. J., Smyth, P., Yu, R., . . . Warschauer, M. (2020). Mining Big Data in Education: Affordances and Challenges. Review of Research in Education, 44(1), 130-160. doi:10.3102/0091732×20903304

Gandomi, A., \& Haider, M. (2015). Beyond the hype: Big data concepts, methods, and analytics. International Journal of Information Management, 35(2), 137-

144.http://dx.doi.org/10.1016/j.ijinfomgt.2014.10.007

Garner, B., Thorne, J. K., \& Horn, I. S. (2017). Teachers interpreting data for instructional decisions: where does equity come in? Journal of Educational Administration, 55(4), 407-426. doi:10.1108/JEA-09-2016-0106

Goodwin, C. (1994). Professional Vision. American Anthropologist, 96(3), 606-633. https://ils.unc.edu/courses/2020_fall/inls720_01W/WebPage s/Readings/MOD08-Goodwin\%201994.pdf

Graves, K. E., \& Bowers, A. J. (2018). Toward a Typology of Technology-Using Teachers in the "New Digital Divide": A Latent Class Analysis (LCA) of the NCES Fast Response Survey System Teachers' Use of Educational Technology in U.S. Public Schools, 2009 (FRSS 95). Teachers College Record, 120(8), 1-42. http://www.tcrecord.org/library/content.asp? contentid $=2227$ 7

Gu, Z., Eils, R., \& Schlesner, M. (2016). Complex heatmaps reveal patterns and correlations in multidimensional genomic data. Bioinformatics, 32(18), 2847-2849. doi:10.1093/bioinformatics/btw313

Halverson, R. (2010). School formative feedback systems. Peabody Journal of Education, 85(2), 130-146. doi: 10.1080/0161956100368527

Hao, J., Smith, L., Mislevy, R., von Davier, A., \& Bauer, M. (2016). Taming Log Files From Game/Simulation-Based Assessments: Data Models and Data Analysis Tools. ETS Research Report Series, 2016(1), 1-17. doi:https://doi.org/10.1002/ets2.12096

Harris Little, M., Cohen-Vogel, L., Sadler, J., \& Merrill, B. (2019). Data-driven decision making in early education: Evidence from North Carolina's pre-k program. Education Policy Analysis Archives, 27(18), 1-23. doi:10.14507/epaa.27.4198

Hawn, A. (2019). Data-wary, Value-driven: Teacher Attitudes, Efficacy, and Online Access for Data-Based Decision Making. (PhD). Columbia University,

Huguet, A., Marsh, J. A., \& Farrell, C. (2014). Building Teachers' Data-use Capacity: Insights from Strong and Developing Coaches. Education Policy Analysis Archives, 22(52), 1-30. http://epaa.asu.edu/ojs/article/view/1600/1278

Ifenthaler, D. (2021). Learning Analytics for School and System Management. In S. Vincent-Lancrin \& R. Baker (Eds.), OECD Digital Education Outlook 2021: Pushing the Frontiers with Artificial Intelligence, Blockchain and Robots (pp. 161-172). Paris, France: Organisation for Economic Co-Operation and Development (OECD) Publishing.

Ikemoto, G. S., \& Marsh, J. A. (2007). Cutting through the "data-driven" mantra: Different conceptions of data-driven decision making. In P. A. Moss (Ed.), Evidence and decision making: The 106th yearbook of the National 
Society for the Study of Education, Part 1 (pp. 105-131). Malden, Mass: Blackwell Publishing.

Jimerson, J. B., Garry, V., Poortman, C. L., \& Schildkamp, K. (in press). Implementation of a collaborative data use model in a United States context. Studies in Educational Evaluation, 69, 100866. doi:10.1016/j.stueduc.2020.100866

Johnson, L., Levine, A., Smith, R., \& Stone, S. (2010). The 2010 Horizon Report. Retrieved from Austin, TX: https://files.eric.ed.gov/fulltext/ED510220.pdf

Jorion, N., Roberts, J., Bowers, A. J., Tissenbaum, M., Lyons, L., Kuma, V., \& Berland, M. (2020). Uncovering Patterns in Constructionist Collaborative Learning Activities via Cluster Analysis of Museum Exhibit Log Files. Frontline Learning Research, 8(6), 77-87. doi:10.14786/flr.v8i6.597

Keim, D. A., Mansmann, F., Schneidewind, J., \& Ziegler, H. (2006, 5-7 July 2006). Challenges in Visual Data Analysis. Paper presented at the Tenth International Conference on Information Visualisation (IV'06).

Koedinger, K. R., D'Mello, S., McLaughlin, E. A., Pardos, Z. A., $\&$ Rosé, C. P. (2015). Data mining and education. Wiley Interdisciplinary Reviews: Cognitive Science, 6(4), 333-353. doi:10.1002/wcs. 1350

Krumm, A. E., Beattie, R., Takahashi, S., D'Angelo, C., Feng, M., \& Cheng, B. (2016). Practical Measurement and Productive Persistence: Strategies for Using Digital Learning System Data to Drive Improvement. Journal of Learning Analytics, 3(2), 116-138. doi:10.18608/jla.2016.32.6

Krumm, A. E., \& Bowers, A. J. (in press). Data-intensive improvement: The intersection of data science and improvement science. In D. J. Peurach, J. L. Russell, L. Cohen-Vogel, \& W. R. Penuel (Eds.), Handbook on Improvement Focused Educational Research. Lanham, MD: Rowman \& Littlefield.

Krumm, A. E., Means, B., \& Bienkowski, M. (2018). Learning Analytics Goes to School: A Collaborative Approach to Improving Education. New York: Routledge.

Lai, M. K., \& Schildkamp, K. (2013). Data-based Decision Making: An Overview. In K. Schildkamp, M. K. Lai, \& L. Earl (Eds.), Data-based Decision Making in Education: Challenges and Opportunities (pp. 9-21). Dordrecht: Springer Netherlands.

Lasater, K., Albiladi, W. S., Davis, W. S., \& Bengtson, E. (2020). The Data Culture Continuum: An Examination of School Data Cultures. Educational Administration Quarterly, 56(4), 533-569. doi:10.1177/0013161x19873034

Lee, J., Recker, M., Bowers, A. J., \& Yuan, M. (2016). Hierarchical Cluster Analysis Heatmaps and Pattern Analysis: An Approach for Visualizing Learning Management System Interaction Data. Paper presented at the International Conference of Educational Data Mining (EDM), Raleigh, NC.

http://www.educationaldatamining.org/EDM2016/proceedin gs/paper 34.pdf

Mandinach, E. B., Friedman, J. M., \& Gummer, E. S. (2015). How Can Schools of Education Help to Build Educators' Capacity to Use Data? A Systemic View of the Issue.
Teachers College Record, 117(4), 1-50. Retrieved from http://www.tcrecord.org/library/abstract.asp?contentid=178 $\underline{50}$

Mandinach, E. B., Honey, M., \& Light, D. (2006). A Theoretical Framework for Data-Driven Decision Making Paper presented at the American Educational Research Association, San Francisco, CA. http://cct.edc.org/sites/cct.edc.org/files/publications/DataFra me AERA06.pdf

Mandinach, E. B., Honey, M., Light, D., \& Brunner, C. (2008). A Conceptual Framework for Data-Driven Decision Making. In E. B. Mandinach \& M. Honey (Eds.), DataDriven School Improvement: Linking Data and Learning (pp. 13-31). New York: Teachers College Press.

Mandinach, E. B., \& Schildkamp, K. (2021). Misconceptions about data-based decision making in education: An exploration of the literature. Studies in Educational Evaluation, 69. doi:10.1016/j.stueduc.2020.100842

Marsh, J. A. (2012). Interventions Promoting Educators' Use of Data: Research Insights and Gaps. Teachers College Record, 114(11), 1-48.

Marsh, J. A., Bertrand, M., \& Huguet, A. (2015). Using Data to Alter Instructional Practice: The Mediating Role of Coaches and Professional Learning Communities. Teachers College Record, 114(4), 1-40. http://www.tcrecord.org/Content.asp?ContentId=17849

Miles, M. B., \& Huberman, A. M. (1994). Qualitative data analysis : An expanded sourcebook. Thousand Oaks, CA: Sage Publications.

Mukherjee, R., \& Kar, P. (2017, 5-7 Jan. 2017). A Comparative Review of Data Warehousing ETL Tools with New Trends and Industry Insight. Paper presented at the 2017 IEEE 7th International Advance Computing Conference (IACC).

Nitkin, D. (2018). Technology-Based Personalization: Instructional Reform in Five Public Schools. (Ph.D.). Columbia University, https://doi.org/10.7916/D8QZ3TC6

Penuel, W. R., Allen, A.-R., Coburn, C. E., \& Farrell, C. (2015). Conceptualizing Research-Practice Partnerships as Joint Work at Boundaries. Journal of Education for Students Placed at Risk, 20(1), 182-197. http://ejournals.ebsco.com/direct.asp?ArticleID=48E095239 2B4F03DE09D

Penuel, W. R., \& Gallagher, D. J. (2017). Creating Research Practice Partnerships in Education. Cambridge, MA: Harvard Education Press.

Penuel, W. R., Riedy, R., Barber, M. S., Peurach, D. J., LeBouef, W. A., \& Clark, T. (2020). Principles of Collaborative Education Research With Stakeholders: Toward Requirements for a New Research and Development Infrastructure. Review of Educational Research, 90(5), 627-674. doi:10.3102/0034654320938126

Piety, P. J. (2019). Components, Infrastructures, and Capacity: The Quest for the Impact of Actionable Data Use on P-20 Educator Practice. Review of Research in Education, 43(1), 394-421. doi:10.3102/0091732x18821116

Piety, P. J., Hickey, D. T., \& Bishop, M. (2014). Educational data sciences: Framing emergent practices for analytics of 
learning, organizations, and systems. Paper presented at the Proceedings of the Fourth International Conference on Learning Analytics and Knowledge.

Popham, W. J. (2010). Everything school leaders need to know about assessment. Thousand Oaks, CA: Corwin.

R Development Core Team. (2019). R: A language and environment for statistical computing. Vienna, Austria: R Foundation for Statistical Computing. http://www.Rproject.org

Reimann, P. (2011). Design-Based Research. In L. Markauskaite, P. Freebody, \& J. Irwin (Eds.), Methodological Choice and Design: Scholarship, Policy and Practice in Social and Educational Research (pp. 3750). Dordrecht: Springer Netherlands.

Riehl, C., Earle, H., Nagarajan, P., Schwitzman, T. E., \& Vernikoff, L. (2018). Following the path of greatest persistence: Sensemaking, data use, and everyday practice of teaching. In N. Barnes \& H. Fives (Eds.), Cases of Teachers' Data Use (pp. 30-43). New York: Routledge.

Schildkamp, K. (2019). Data-based decision-making for school improvement: Research insights and gaps. Educational Research, 61(3), 257-273. doi:10.1080/00131881.2019.1625716

Schildkamp, K., \& Ehren, M. C. M. (2013). From "intuition" to data-based decision making in Dutch secondary schools? In K. Schildkamp, M. K. Lai, \& L. Earl (Eds.), Data-based decision making in education: Challenges and opportunities (pp. 49-67). Dordrecht: Springer.

Schildkamp, K., \& Kuiper, W. (2010). Data-informed curriculum reform: Which data, what purposes, and promoting and hindering factors. Teaching and Teacher Education, 26(3), 482-496. doi:https://doi.org/10.1016/j.tate.2009.06.007

Schildkamp, K., \& Poortman, C. (2015). Factors Influencing the Functioning of Data Teams. Teachers College Record, 117(4), 1-42. Retrieved from http://www.tcrecord.org/Content.asp?ContentId=17851

Schildkamp, K., Poortman, C., Luyten, H., \& Ebbeler, J. (2017). Factors promoting and hindering data-based decision making in schools. School Effectiveness and School Improvement, 28(2), 242-258. doi:10.1080/09243453.2016.1256901

Schildkamp, K., Poortman, C. L., \& Handelzalts, A. (2016). Data teams for school improvement. School Effectiveness and School Improvement, 27(2), 228-254. doi:10.1080/09243453.2015.1056192

Schutt, R., \& O'Neil, C. (2013). Doing Data Science: Straight Talk from the Frontline. Cambridge, MA: O'Reilly.

Selwyn, N., Pangrazio, L., \& Cumbo, B. (2021). Attending to data: Exploring the use of attendance data within the datafied school. Research in Education, 109(1), 72-89. doi:10.1177/0034523720984200

Siemens, G. (2013). Learning Analytics: The Emergence of a Discipline. American Behavioral Scientist, 57(10), 13801400. doi:10.1177/0002764213498851
Supovitz, J., \& Morrison, K. (2015). Does Collaboration Facilitate Data Use in Schools? Journal of Studies in Education, 5(2), 136-156. doi:10.5296/jse.v5i2.7379

Tichnor-Wagner, A., Wachen, J., Cannata, M., \& Cohen-Vogel, L. (2017). Continuous improvement in the public school context: Understanding how educators respond to plan-dostudy-act cycles. Journal of Educational Change, 18(4), 465-494. doi:10.1007/s10833-017-9301-4

Tukey, J. W. (1962). The Future of Data Analysis. The Annals of Mathematical Statistics, 33(1), 1-67. Retrieved from http://www.jstor.org/stable/2237638

Tukey, J. W. (1977). Exploratory data analysis (Vol. 2): Reading, Mass.

Vassiliadis, P. (2009). A survey of extract--transform--load technology. International Journal of Data Warehousing and Mining, 5(3), 1-27. Retrieved from https://link.gale.com/apps/doc/A203177969/AONE?u=new3 0429\&sid=AONE\&xid=5768faf9

Wachen, J., Harrison, C., \& Cohen-Vogel, L. (2018). Data Use as Instructional Reform: Exploring Educators' Reports of Classroom Practice. Leadership and Policy in Schools, 17(2), 296-325. doi:10.1080/15700763.2016.1278244

Walonoski, J. A., \& Heffernan, N. T. (2006). Prevention of OffTask Gaming Behavior in Intelligent Tutoring Systems, Berlin, Heidelberg.

Warnes, G. R., Bolker, B., Bonebakker, L., Gentleman, R., Huber, W., Liaw, A., . . Venables, B. (2020). gplots: Various R Programming Tools for Plotting Data. https://CRAN.R-project.org/package=gplots

Wayman, J. C., Shaw, S., \& Cho, V. (2017). Longitudinal Effects of Teacher Use of a Computer Data System on Student Achievement. AERA Open, 3(1). doi:doi:10.1177/2332858416685534

Wayman, J. C., \& Stringfield, S. (2006). Data use for school improvement: School practices and research perspectives. American Journal of Education, 112(4), 463-468. Retrieved from http://www.journals.uchicago.edu/AJE/journal/contents/v11 2n4.html

Wilkerson, S. B., Klute, M., Peery, B., \& Liu, J. (2021). How Nebraska teachers use and perceive summative, interim, and formative data (REL 2021-054). Retrieved from Washington, DC: https://ies.ed.gov/ncee/edlabs/projects/project.asp?projectID $=5683$

Wilkinson, L., \& Friendly, M. (2009). The History of the Cluster Heat Map. The American Statistician, 63(2), 179-184. doi:10.1198/tas.2009.0033

Yin, R. K. (2017). Case study research and applications: Designs and methods (6th ed.). Thousand Oaks: Sage. 